\title{
Priložnostne skladbe v čast cesarju, monarhiji in panslavizmu kot odraz nekaterih staroslovenskih političnih načel in idej po letu 1848
}

\section{Occasional Music in Honour of the Monarchy, the Emperor and Pan-Slavism as a Reflection of Some Slovenian Political Ideas After 1848}

Ključne besede: glasba 19. stoletja, glasba in politika, glasbeni nacionalizem, priložnostna glasba, himne

\section{IZVLEČEK}

Priložnostne skladbe za politično rabo z izrazito zunajumetniško tendenco - hvalnice v čast cesarju, monarhiji in panslavizmu - kažejo drugačno podobo in imajo drugačen pomen kot pretežni del izvirne slovenske ustvarjalnosti »v službi naroda« po letu 1848. $\mathrm{V}$ primerjavi z domoljubnimi pesmimi in pesmimi v ljudskem duhu predstavljajo takšne priložnostne pesmi zanemarljiv in z umetniško-razvojnega vidika nepomemben del slovenske glasbene ustvarjalnosti; od pomladi narodov do razpada monarhije jih je nastalo manj kot dvajset. Pisali so jih priseljeni češki glasbeniki in priložnostni, manj pomembni ustvarjalci, ki jim je bil blizu legitimizem staroslovenskega političnega programa. Drugačen primer funkcionalne glasbe za politično rabo predstavljajo uglasbitve politično angažiranih besedil, ki so nastale zaradi vpliva aktualne politične ideje slovanske vzajemnosti zlasti v petdesetih in šestdesetih letih 19. stoletja.
Keywords: 19th-century music, music and politics, nationalism, occasional music, hymns

\section{ABSTRaCT}

Occasional musical works for the political use with the explicit extra musical purpose - hymns in honour of the Hapsburg monarchy and the emperor Franz Joseph - show a different image and has a different meaning than the prevailing part of the Slovenian music creativity after 1848 . In comparison with the patriotic songs with the national-awakening lyrics and songs in folkloric manner they represent only a negligible and trivial part of the Slovenian music creativity. They were the work of the immigrant Czech composers and unimportant music creators whose opinion corresponded with the legitimism of the Slovenian conservative thinking after 1848. These are extreme examples of the functional music. Another example of music in the political use are occasional songs on the politically committed subjects that promoted pan-Slavism and sprang up mostly in the fifties and sixties of the nineteenth century.

Vpliv političnega dejavnika na glasbeno kulturo druge polovice 19. stoletja na Slovenskem se zdi samoumeven, usidran v slovenski zgodovinski zavesti, vendar ostaja vprašanje razsežnosti odnosov glasbe in politike v muzikoloških zapisih omejeno na 
kratka splošna družbenozgodovinska opažanja. Kvantitativno skromno število tovrstnih raziskav v muzikološki stroki nasploh ${ }^{1}$ ne pomeni nezainteresiranosti raziskovalcev, ampak dejstvo, da je vprašanje odnosa glasbe in politike največkrat vpleteno v različno drugo problematiko; v razpravah, ki se nanašajo na glasbo devetnajstega stoletja, zlasti v problematiko glasbenega nacionalizma. Po drugi strani pa je zaradi svojih razsežnosti vprašanje razmerij glasbe in politike na presečišču različnih ved in je danes aktualno tudi v različnih sodobnih disciplinah, ki proučujejo glasbo v širšem kulturnem kontekstu, npr. v antropologiji ali kulturnih študijah. Dejstvo, da ne gre za muzikološko tematiko v ožjem pomenu besede, lahko raziskovalca - muzikologa spravlja v dvome, še zlasti zato, ker se vprašanje ne more dokončno vsestransko racionalno in empirično raziskati.

Relevantnost raziskovanja političnega dejavnika v slovenski glasbeni kulturi druge polovice 19. stoletja potrjuje dejstvo, da je bila vzpostavitev neodvisne slovenske kulture osrednje vodilo nacionalne politike po letu 1848. Status kulture je bil utemeljen z njeno vlogo v narodnem gibanju. Etnični koncept domovine je izhajal iz mišljenja maloštevilne inteligence, da naj bi slovenski narod naredila prepoznaven kultura. Bistven pomen v teh načrtih je imela torej drugačnost, ki je sprva izhajala zgolj iz jezika. Gre za zgodnjo fazo nacionalizma, v kateri je bila pozornost posvečena enotnemu jeziku, ki bi povezal slovenske dežele z različnimi dialekti ter s tem omogočil organsko kulturno enotnost naroda. Slovenski jezik je bil zunanji znak, po katerem je bila kultura prepoznavna. Nacionalnost je bila poudarjena na zunaj.

V skladu s kulturnimi prizadevanji je bila vloga glasbe določena na tri načine: z idejami o združevanju v eno, slovensko kulturo na podlagi skupnega slovenskega knjižnega jezika, z idejami o kulturni avtonomiji, se pravi z idejami o vzpostavitvi neodvisne slovenske kulture in s predstavami o simbolični moči etnične (ljudske) kulture. Etnični repertoar je bil razumljen kot vir ohranitve, kot vir političnega izraza. Vpetost politike v slovensko kulturo po letu 1848 je bila neizpodbitna in je vplivala na nesamostojnost vseh področij umetniškega ustvarjanja. V načrtih za slovensko kulturo je imela vitalen pomen literatura. Slovenski literarni zgodovinar France Bernik je zapisal, da je »slovenska književnost poleg umetniške uresničevala še državnotvorno funkcijo. «²

Utilitaristične tendence kulturne politike po letu 1848 so segle tudi na področje glasbe in povzročile njeno podrejenost oziroma odvisnost od zunajglasbenih, predvsem političnih in socialnih dejavnikov. Njihov vpliv je bil v pretekli slovenski glasbeni kulturi v tolikšni meri zaznaven predvsem zaradi dveh bistvenih razlogov - najprej in predvsem zaradi odsotnosti glasbene tradicije ter po drugi strani zaradi pomena jezika v nacionalnih (kulturnih) prizadevanjih. Glasbeni nacionalizem ${ }^{3}$ na Slovenskem v drugi polovici 19. stoletja ni bil zapoznel odmev "glasbenega obrobja« na močna nacionalna gibanja v evropski glasbi, ki so bila zaradi trdne glasbene tradicije neodvisna in imanentno prisotna. V idejah o slovenski kulturi je bila merilo za ločevanje domačega in tujega »narodna pesem», ki pa

1 Vprašanje odnosov glasbe in politike je bila tema strokovnega posvetovanja Über Musik und Politik leta $1971 \mathrm{v}$ Darmstadtu in konference Musik und Politik. Dimensionen einer undefinierten Beziehung pred desetimi leti v Regensburgu. Prav tam je leta 1997 izšel zbornik referatov s prispevki v treh tematskih sklopih: "politična glasba", "družba, glasba in politika" in "glasbena politika«, ki zarisujejo možne cilje raziskav odnosov glasbe in politike. Gl. Musik und Politik. Dimensionen einer undefinierten Beziehung, ur. Bernhard Frevel (ConBrio-Fachbuch 6). Regensburg: ConBrio Verlagsgesellschaft, 1997.

France Bernik. 'O recepcijskih modelih v slovenski književnosti'. V: Slavistična revija 45/1-2 (1997), 307-312.

O ponovni aktualnosti tematike glasbenega nacionalizma pričajo tudi prispevki muzikologov iz različnih evropskih držav v zborniku, ki je bil izdan pred petimi leti. Gl. Musical Constructions of Nationalism: Essays on the History and Ideology of European Musical Culture 1800-1945, ur. Harry White in Michael Murphy. Cork: Cork University Press, 2002. 
še ni bila raziskana in podrobno opredeljena. V prvih desetletjih po letu 1848 je konservativno usmerjena slovenska politika podpirala v vseh ozirih preprosto glasbo, oprto na ljudsko pesem, v glasbeno-tehničnem pogledu skrajno enostavno. Prednostni zahtevi sta bili množičnost in razumljivost, ki sta glasbo potisnili v funkcionalno odvisnost. Vokalna, pretežno zborovska ustvarjalnost, ki je nastala v obdobju glasbenega rodoljubja kaže, da se je večina glasbenih ustvarjalcev podredila takšnim normam oblikovanja.

Poleg raziskav normativov nacionalne kulturne politike ter glasbene politike posameznih društev in institucij je možen cilj raziskav odnosov glasbe in politike v drugi polovici 19. stoletja na Slovenskem tudi bolj kompleksno opazovanje vplivov političnih nazorov in idej na samo glasbo oziroma glasba za politično rabo. Tovrstno raziskovanje sega iz statičnega glasbeno-zgodovinskega umetniškega okvira na časovno odvisno področje recepcije in percepcije glasbe. Pesem je bila vir politične propagande in manipulativna moč političnih idej, na zunaj razvidna skozi sporočilnost besedila. V sintezi glasbe in besede je bila glasba sposobna okrepiti angažiranost zunajglasbenega sporočila. Gre tudi za vprašanje, kakšno aktivistično moč je imela glasba, natančneje melodija kot nosilka besednega sporočila, kot sprožilec navdušenja, celo evforije, za politično mišljenje oziroma gibanje.

Od srede do sedemdesetih let 19. stoletja je narodno-prebudna, svetovnonazorsko konservativna politika, ki jo je utemeljeval Janez Bleiweis v svojem poljudnem časniku Novice, zaznamovala slovenski duhovni prostor. Politični program njegovega kroga somišljenikov staroslovencev, ki ga je izražalo geslo »Vse za vero, dom, cesarja!«, je temeljil na vdanosti avstrijski monarhiji, zavezništvu s cerkvijo, skrbi za gospodarski napredek in utilitarnem pojmovanju kulture. Fazo zgodnjega nacionalizma zaznamuje tudi zavzemanje za politično in kulturno povezovanje s slovanskimi narodi v okviru monarhije, ki naj bi služilo kot zaščita pred germanizacijo.

Ob glavnem toku izvirne glasbene vokalne ustvarjalnosti v ljudskem duhu »v službi naroda« so bile hvalnice v čast cesarju in državi - stari Avstriji ter druge priložnostne pesmi, v katerih politične ideje in prepričanja razkrivajo zunajglasbeni znaki - naslov, besedilo, posvetilo in priložnosti - le sporadičen pojav. Za pretekle raziskovalce zgodovine slovenske glasbene umetnosti so pomenile te priložnostne pesmi v zapisih komaj omembe vreden vir, in - glede na njihove metode in cilje tovrstnega raziskovanja - tudi upravičeno zapostavljen vir. Podobno je bilo v slovenski literarni zgodovini. Pesmi v čast cesarju in državi stari Avstriji so bile ob svojem nastanku in hkratni objavi deležne velike pozornosti, toda bile so hitro pozabljene. Marjan Dolgan je zapisal v antologiji slovenske slavilne državniške poezije, da "sestavljajo 'temno stran meseca' v vesolju slovenske literature « ${ }^{4} \mathrm{~V}$ nasprotju s slovensko literaturo, kjer sestavljajo slavnostne državne pesmi njen obsežen del, ki »ga ni mogoče več spregledovati «, 5 pa so v glasbeni ustvarjalnosti druge polovice 19. stoletja tovrstne priložnostne pesmi redke. Čeprav nimajo umetniške vrednosti in so nepomembne za slovensko glasbeno zgodovino, so tovrstne priložnostne skladbe lahko prepričljiv vir za preučevanje kulturne zgodovine, zgodovine idej in mentalitet. V koordinatah kulturno-zgodovinskega raziskovanja je smiselno raziskovalni interes usmeriti na to, kdo je pisal tovrstne priložnostne pesmi, ob kakšni priložnosti, kje so bile objavljene in kakšen je bil odziv nanje.

Marjan Dolgan. Slovenska muza pred prestolom. Antologija slovenske slavilne državniške poezije. Ljubljana: Univerzitetna konferenca ZSMS, Knjižnica revolucionarne teorije (Knjižna zbirka Krt 57), 1988, 262.

Isto, 263. 


\section{Na slavo Avstriji ${ }^{6}$}

V literaturi druge polovice 19. stoletja je po navedbah Igorja Grdine »močno cvetel cesarski kult «, ${ }^{7}$ slavilne pesmi v čast državi so bile redkejše kot pa priložnostne pesmi v čast cesarju. Kot razlog navaja Grdina vladno politiko, ki je nasprotovala nacionalističnim prizadevanjem, zaradi česar si državljanska pripadnost ni mogla pridobiti statusa konstitutivnega elementa slovenske narodne zavesti, "vsaj v zavesti rodoljubnih elit ne ${ }^{8}$ Nacionalno ozaveščeni glasbeni ustvarjalci so za potrebe čitalnic pisali pesmi s klavirjem in zbore na domoljubna besedila (seveda v slovenskem jeziku), ki so opevala lepote slovenske dežele in budila k povezovanju s slovanskimi narodi.

Kljub temu zgodovina recepcije dokazuje, da so se Slovenci identificirali s svojo uradno državno himno - staro avstrijsko himno vse do razpada monarhije. ${ }^{9}$ Prvič so jo peli še v nemškem jeziku v Ljubljani že v letu njenega nastanka, leta 1797, takrat je prevod prvih štirih vrstic v slovenski jezik objavil Valentin Vodnik v časopisu Lublanske Novize. Pol stoletja kasneje so himno objavili na začetku prvega zvezka zbirke Slovenska gerlica z naslovom Slovencov národna pesem in s pripisom "napev stari«, torej brez navedbe skladatelja Haydna. ${ }^{10}$

Tudi v drugem zvezku iste zbirke je pesem z naslovom Cesarska pesem objavljena brez navedb avtorjev. Arhivski in časopisni viri pričajo, da so himno s tem naslovom peli na čitalniških prireditvah, ponavadi na začetku ali koncu sporeda in jo natisnili v različnih pesmaricah. Tudi ob priliki cesarjevega obiska so jo peli v slovenskem jeziku. ${ }^{11}$ Z avstrijsko himno se je končal Venec narodnih slovanskih pesem Antona Nedvěda, ki je na prvi bésedi celjske čitalnice leta 1862 zelo »dopadel «. ${ }^{12}$ Leta 1883 , v letu praznovanja šeststoletnice začetka habsburške vlade na Štajerskem in Kranjskem, je Foersterjevo harmonizacijo takrat aktualne državne himne za mešani zbor objavila revija Cerkveni glasbenik, tokrat z navedbo skladatelja Haydna in z naslovom Avstrijska himna.

Poleg sekundarnih časopisnih virov o recepciji naše pretekle državne himne pričajo tudi primarni glasbeni viri, variacije in parafraze na himnično melodijo. Posledica domoljubnih čustev, razplamtelih zaradi atentata na cesarja Franca Jožefa leta 1853, in vdanosti monarhu je priložnostna skladba z obširnim naslovom, ki ima že sam po sebi dokumentarno vrednost Gefühle der Wehmuth über das ruchlose Attentatvom 18. Febr. 1853. seiner k. k. apostolisch majestät Franz Josef I. Fantasie mit Variationen über die allbeliebte Volks-Hymne für das Pianoforte. Župnik iz Stične Johann (Janez) Hinek jo je označil kot svoje prvo delo. Zanimiva podrobnost, ki se nanaša na zgodovino recepcije, je ustvarjalčeva oznaka za uradno državno staro avstrijsko himno v naslovu - »splošno priljubljena narodna himna«. Dobrih dvajset strani dolge variacije na Haydnovo melodijo je izdala dunajska založba F. Glöggl. Marjan Lipovšek

6 Slavilno pesem z naslovom Na slavo Avstriji je napisal Anton Foerster na besedilo Antona Funtka ob priliki štiridesetletnice vladanja Franca Jožefa leta 1888 in jo objavil v reviji Cerkveni glasbenik.

Igor Grdina. Od rodoljuba z dežele do meščana. Ljubljana: Studia humanitatis (Apes 13), $1999,28$.

Isto, 27.

Nataša Cigoj Krstulović. 'Himna kot simbol naroda: premislek ob stoletnici Premrlove Zdravice'. V: De musica disserenda I/1 (2005), 14.

10 Takrat so s himno slavili še avstrijskega cesarja Ferdinanda. Po njegovi smrti kmalu zatem so začetni verz pesmi »Slava našimu cesarju Ferdinandu milimu« zamenjali z »Bog ohrani, bog obvari nam cesarja, Avstrijo! . Himna s spremenjeno različico besedila je bila objavljena v drugem zvezku Slovenske gerlice, ki je izšel skupaj s prvim zvezkom v Ljubljani jeseni 1848.

11 Poročevalec je ob cesarjevem obisku v Mariboru leta 1856 zapisal: »[...] Mestna kapela je zagodla 'cesarsko pesem' in še nekoliko drugih, potem pa so pred poslopje stopile slovenske deklice v narodni noši in so začele po slovenski popevati 'cesarsko pesem'." Gl. Novice kmetijskih, obertnijskih in narodskih reči 14/75 (1856), 301.

12 Gl. Novice gospodarske, obertniške in narodne 20/9 (1862), 68. 
N. CigOJ KRSTULOVIĆ • PRILOŽNOSTNE SKLAdBE V ČAST ...

je v svojem zgodovinskem orisu slovenske klavirske glasbe to Hinekovo skladbo pozitivno vrednotil in napisal, da »kaže znatno obvladanje klavirsko-tehničnih zahtev« ${ }^{13} \mathrm{~V}$ primerjavi s preteklo izvirno klavirsko ustvarjalnostjo kaže ta skladba res opazen napredek, vendar dvanajst variacij ne presega klišejske manire variacijskega ornamentiranja. Gl. Primer 1.
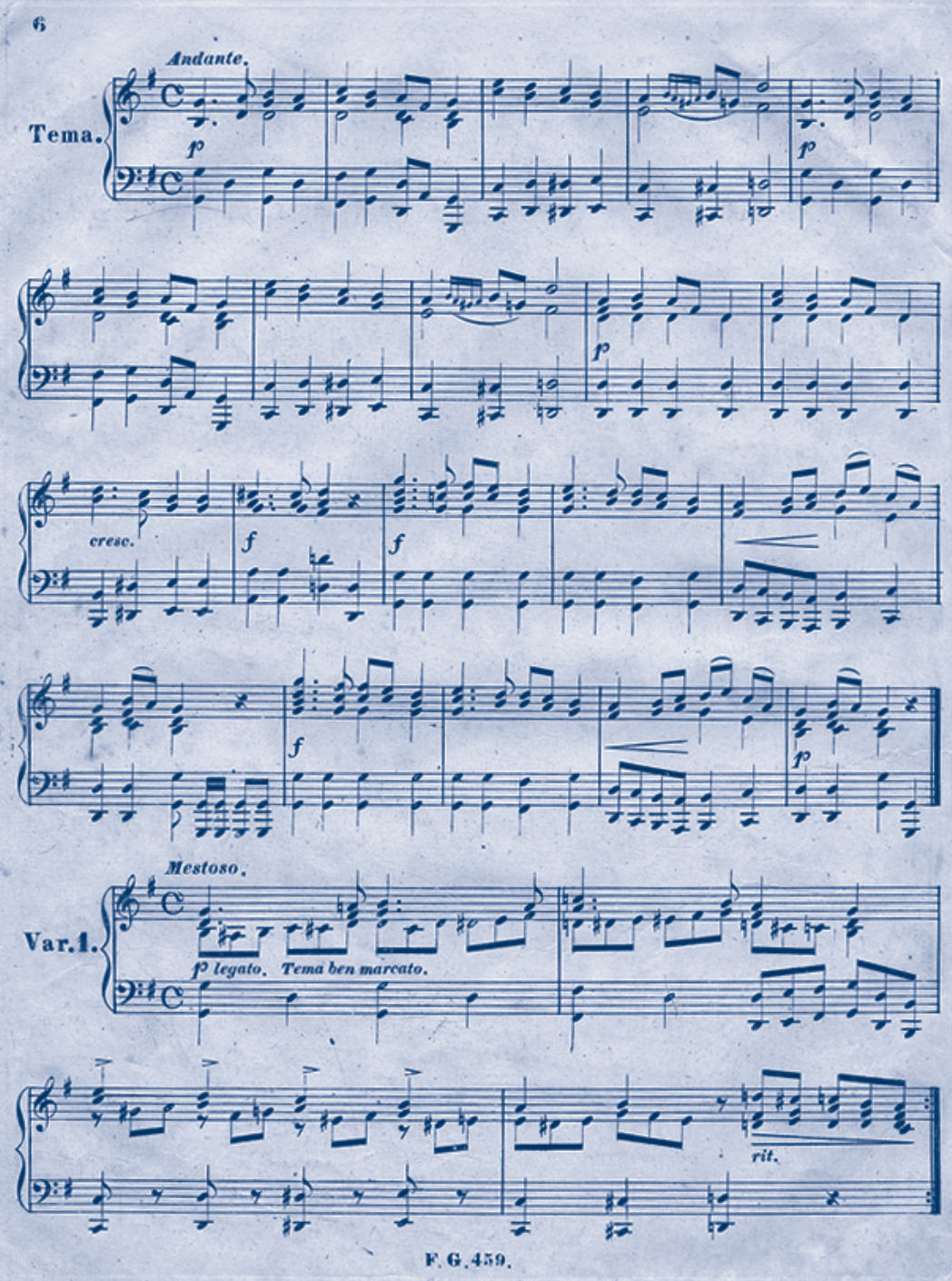

\section{Primer 1.}

Johann Hinek: Gefühle der Wehmuth über das ruchlose Attentat vom 18. Febr. 1853. seiner k. k. apostolisch majestät Franz Josef I. (Dunaj, F. Glöggl, 1853, str. 6)

13 Marjan Lipovšek. 'Slovenska klavirska glasba'. Muzikološki zbornik 2 (1966), 66. 
Povsem jasno je, da so bila besedila priložnostnih slavilnih pesmih, ki so bile napisane za izvedbo v čast cesarjevega obiska, ob obletnici njegovega vladanja in ob posebnih dogodkih v zvezi z njegovo družino, podrejena izpolnjevanju smotra - poveličevanju slavljenca in s tem brez posebne umetniške vrednosti. Kot pojasnjuje Marjan Dolgan v svoji antologiji, slavilne državniške poezije niso pisali inovativni avtorji ampak predvsem avtorji, ki so izhajali iz kroga staroslovencev ter epigonski in manj izraziti avtorji. ${ }^{14}$ $\mathrm{V}$ nasprotju z literaturo pa takšne sicer redke slavilne pesmi najdemo tako med deli priložnostnih glasbenih ustvarjalcev kot tudi v opusih pomembnejših skladateljev kot so Kamilo Mašek, Anton Nedvěd, Anton Foerster, Hugolin Sattner in Fran Gerbič. PriloŽnostne skladbe teh ustvarjalcev so bile plod zunajumetniške spodbude in naklonjenosti političnem mišljenju staroslovencev. Ob obisku vladarskega para leta 1856 je Kamilo Mašek na besedilo Heinricha Coste napisal slavnostno pesem Jubelhymne, ki jo je zapelo sedemdeset pevcev pred deželnim dvorcem. Pesem je deželni glavar »lično pisano in vezano " poklonil vladarskemu paru. ${ }^{15}$ Drugačni rabi je bila namenjena trivialna skladba, ki jo je tiskar Blaznik natisnil naslednje leto. Kratko priložnostno klavirsko skladbo z obsežnim naslovom, ki je opominjal na spodbudo njenega nastanka, Glasi radostni o vernitvi Nju. C. k. apost. Velič. Franc Jožefa in Elizabete med Kranjce leta 1857, je napisal učitelj, organist in ustvarjalec priložnostnih cerkvenih skladb Josip Levičnik. Označil jo je »slovenska polka s petjem«. Dvodelna skladba ima v drugem delu podloženo kratko banalno besedilo (verjetno Levičnikovo), ki izraža ljubezen do vladarskega para.

Med slovenskimi skladbami, ki so nastale po letu 1848, so patriotske hvalnice v čast stari Avstriji redke. Vdanost monarhiji je bila povod za nastanek v vseh ozirih preproste dvoglasne hvalnice stari Avstriji Moja Avstrija, ki jo je na besedilo Hrabroslava Perneta uglasbil Srečko Stegnar. Leta 1878 jo je objavila »revija za šolo in dom« Učiteljski tovariš.

Nemška glasbena družba Philharmonische Gesellschaft je redko počastila državo, cesarja in dinastijo z organizacijo izrednega slavnostnega koncerta. Ob srebrni obletnici cesarjeve poroke leta 1879 je organizirala slavnostni koncert pod vodstvo takratnega glasbenega ravnatelja Antona Nedvěda. ${ }^{16} \mathrm{Na}$ programu je bila tudi njegova hvalnica državi v nemškem jeziku Mein Österreich. Ta moški zbor so večkrat izvajali na izrednih in slavnostnih koncertih v čast cesarju in njegovi družini, pa tudi pevskih večerih te družbe. Prvič ga zasledimo v programu izrednega koncerta za ranjence v SchleswigHolsteinu že leta 1864, zadnjič na serenadi ob cesarjevem obisku leta $1883 .{ }^{17}$ Skladbo je natisnil dunajski založnik F. Glöggl. Avtor besedila ni naveden. Domnevno bi lahko bil organizator in tajnik Philharmonische Gesellschaft, Friedrich Keesbacher, saj Nedvěd sicer sam ni pisal besedil za svoje skladbe. Gl. Primer 2.

14 Marjan Dolgan. Slovenska muza ... Op. cit., 267.

15 Gl. Novice kmetijskih, obertnijskih in narodskih reči 14/19 (1856), 372.

16 Zanimivo je, da so bili na sporedu slavnostnega koncerta ob srebrni obletnici cesarjeve poroke poleg nemških skladb tudi trije slovenski zbori in sicer: Foersterjev Pobratimija na besedilo Simona Jenka in dva Nedvědova zbora Na goro na besedilo Miroslava Vilharja in Oblakom na besedilo Gregorja Kreka. Te zbore je kasneje objavila založba Glasbena matica.

17 Gl. Primož Kuret. Ljubljanska Filharmonična družba 1794-1919. Kronika ljubljanskega glasbenega življenja v stoletju meščanov in revolucij. Ljubljana: Nova revija, 2005, 605-660. 
2

\section{MEIN ÖSTERREICH componirt von}

\section{Anton Nediếo. \\ Op. 9.}
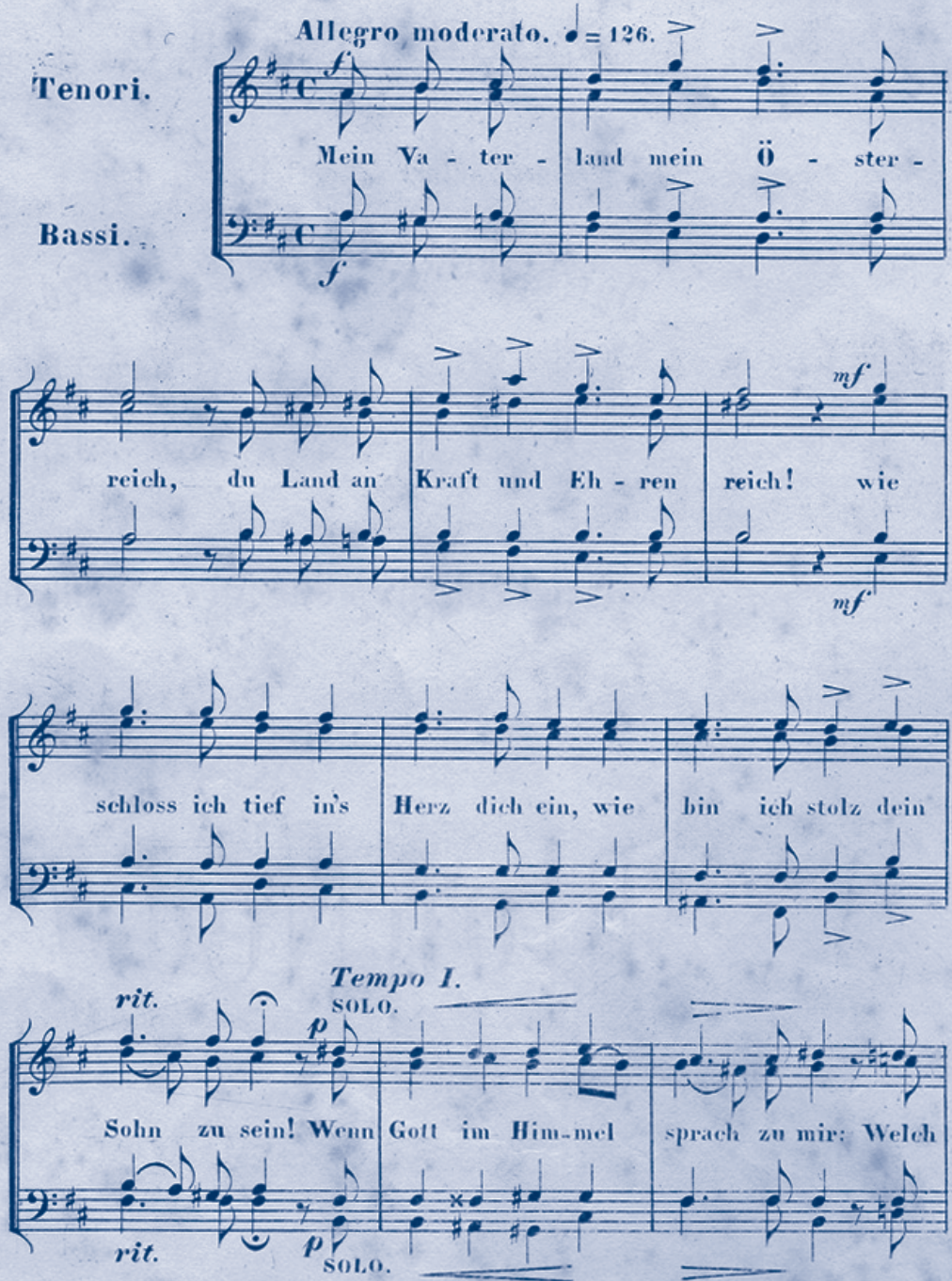

Gedrnckt bei F. G10̈ggl in Wien.

F. G. 19 i.9.

Primer 2.

Anton Nedvêd: Mein Österreich, op. 9. (Dunaj, F. Glögl, [s. a.], str. 2.) 
Praznovanje srebrne poroke vladarskega para je spodbudilo tudi Frana Gerbiča, ki je $\mathrm{v}$ ta namen napisal moški zbor Himna $v$ slovesno praznovanje njih veličanstev cesarja in cesarice na besedilo Krašovica (?). Avtograf skladbe, kjer je pripisan datum 24. 4. 1879, hranijo v Narodni in univerzitetni knjižnici.

Dve leti kasneje je bila poroka v cesarski družini povod za dve novi priložnostni skladbi in slavnostni koncert. Z izrednim koncertom je slavnostni dogodek počastila Philharmonische Gesellschaft in pod skladateljevim vodstvom izvedla Nedvědovo Himno za mešani zbor. To priložnostno skladbo je objavila revija Učiteljski tovariš. Ob isti priložnosti je prigodniško besedilo Luke Jerana Himna o slavnej poroki Njegove visokosti prejasnega cesareviča Rudolfa s prejasno kraljevo princesinjo Štefanijo Belgijansko uglasbil Anton Foerster. Skladba je bila natisnjena v glasbeni prilogi revije Cerkveni glasbenik. Tega leta je bila v prilogi celjske revije "za šolo in dom« Popotnik natisnjena hvalnica Gustava Ipavca Avstrija moja, posebnost v opusu tega čitalniškega skladatelja, ki je sicer uglasbil večinoma domoljubna besedila, ki so afirmirala slovensko deželo in slovenski narod.

Leta 1883 je bila v čast cesarjevega obiska slavnostna akademija v Deželnem gledališču, kjer so izvedli tudi priložnostno kantato za soliste in moški zbor Frana Gerbiča. Razen pomanjkljive navedbe v koncertnem listu ni moč ugotoviti natančneje, kakšna je bila slavnostna skladba, saj ni ohranjena v skladateljevi zapuščini, ki jo hranijo v Narodni in univerzitetni knjižnici. Istega leta je Anton Foerster objavil v reviji Cerkveni glasbenik priložnostno skladbo v slavo šeststoletni zvezi vojvodine Kranjske s Habsburžani z naslovom Kranjska z Avstrijo (bes. Mihael Markič ${ }^{18}$ ) in s podnaslovom slovenska himna (!), z njo pa še harmonizacijo Avstrijske himne za mešani zbor. Skladbi je še posebej natisnil za prodajo tudi tiskar Milic. Skladateljeva opomba, da se lahko skladba izvaja enoglasno s klavirsko spremljavo, dvo-, tri-, štiri- ali petglasno, kot deški, moški ali mešani zbor, kaže funkcionalnost izvedbene ravni, ki se ji je ustvarjalec podredil.

Štirideseto obletnico cesarjeve vladavine je počastilo s priložnostnim koncertom Delavsko pevsko društvo Slavec, urednik revije Cerkveni glasbenik Foerster pa ji je posvetil glasbeno prilogo leta 1888 in objavil tri priložnostne himnične zbore: zbor Angelika Hribarja Oj živi Bog cesarja na besedilo Ivana Zarnika, zbor Antona Foersterja Na slavo Avstriji na besedilo Antona Funtka in zbor Hugolina Sattnerja O Avstrija, ti dom krasan na besedilo Josipa Pintarja. »Branje« takšnih priložnostnih slavnostnih pesmi je relativno preprosto in ne prinaša presenetljivih rezultatov. Nesamostojnost glasbe in njeno podrejenost besednemu delu je določal prednostni zunajumetniški namen. Nedomiselna in v izrazju zelo omejena besedila, so bila plod spontanega navdušenja prigodniških pesnikovalcev. V takih funkcionalnih okvirih so imeli skladatelji, četudi vešči obrtniki, le skromen nabor kompozicijskih možnosti. Skladatelji so morali uglasbitev podrediti prednostni vlogi besedila in upoštevati deklamatoričen princip slavilnih pesmi, v katerih je poudarek na posameznih besedah. Na slovesen značaj skladbe opozori pogosta oznaka maestoso na začetku skladbe. Glasbena struktura teh priložnostnih skladb sloni na klišejskem ponavljanju melodičnih obrazcev, statični harmoniji glavnih stopenj tonalitete in stereotipnem koračniškem ritmu. Gl. Primer 3.

18 Besedilo slavnostne pesmi Kranjska $z$ Avstrijo je napisal filozof Mihael Markič še kot dijak. V zrelih letih se s kovanjem rim ni več ukvarjal. Gl. Stanko Glonar. 'Markič Mihael'. Slovenski biografski leksikon, 2. zv. Ljubljana: Slovenska akademija znanosti in umetnosti, 1952, 48-49. 
44

\section{Na slavo Avstriji.")}

(Ant. Funtek.)
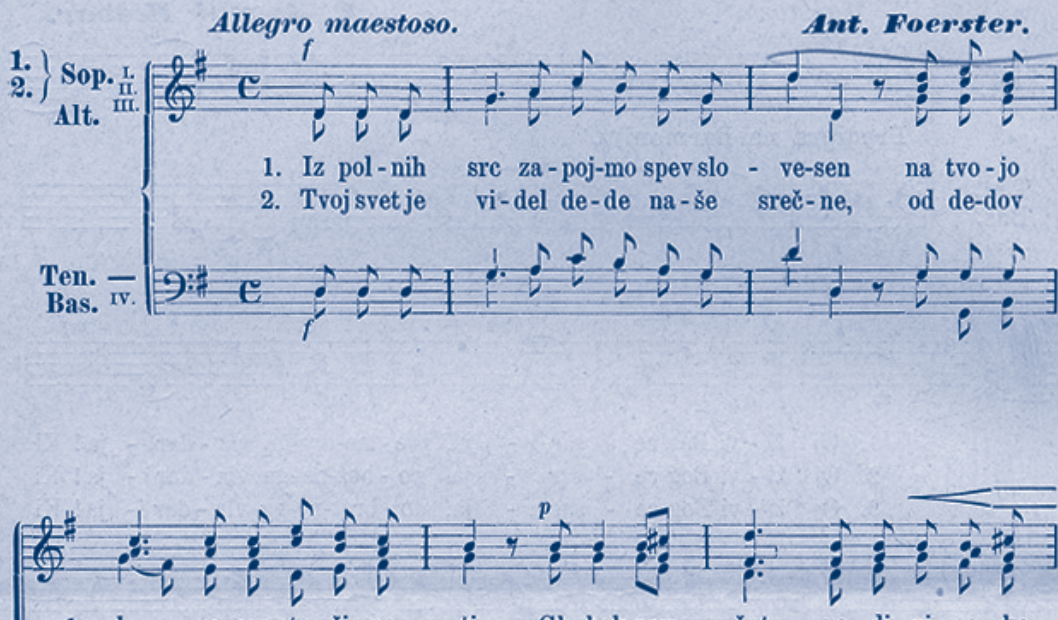

1. sla - vo, car-stvo šir-no ti. Glo-bok nam čut ro-di vi-so-ko

2. smo spre-je-li mi bla - gost. Ne te sa - mo, o-bet zve-sto- be
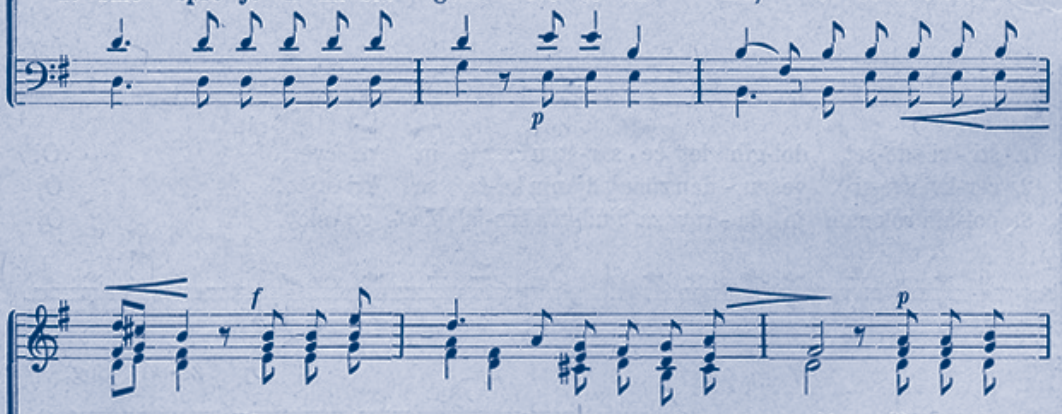

1. pe - sen, kar sr-ce po-je, vsr-ce naj zve - ni! Tu rast in

2. več- ne srč-no po - ra-ja tu-di namzve - stost. Kjer-ko-li

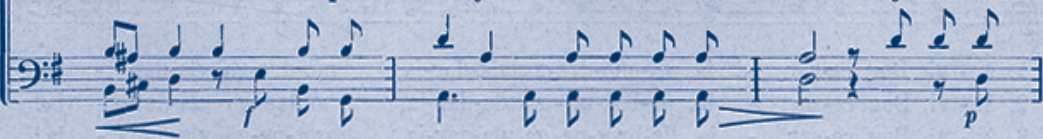

*) More se izrsiti razun peteroglasno tudi čveteroglasno (sostavno ali razstavno) brez tenorja ali pa triglasno (kot moški ali żenski trospev) brez tenorja in basa. Sè spremljanjem harmonija ali klavirja se pesem izvrši še enoglasno.

Primer 3.

Anton Foerster: Na slavo Avstriji. (Cerkveni glasbenik, 11/1888, priloga 11 in 12, str. 44.) 
Polstoletna obletnica vladanju cesarja leta 1898 je bila navdih še za dve priložnostni skladbi za moški zbor ter sopran in alt ad libitum Janeza Laharnarja Jubilejska kantata in Moja Avstrija, ki ju je ustvarjalec objavil v samozaložbi. Ker avtor besedila ni naveden, lahko domnevamo, da je ustvaril Laharnar sam tudi besedili. Slednji, tako kot sama glasba, s svojo plehkostjo kažeta na to, da sta bili deli plod spontanega občudovanja monarha in ne moči ustvarjalčeve umetniške nadarjenosti. Evgen Lampe je skladbi v reviji Dom in svet označil kot »ognjevita, krepka zbora, melodijozna, lahka za izvršitev, primerna za cesarske slavnosti. ${ }^{19}$ Pozabljeni priložnostni trivialni skladbi sta danes le zanimivost kulturne zgodovine.

Slovenska društva so prireditve v čast cesarju in monarhiji organizirala le izjemoma. V časopisnih virih zasledimo, da je leta 1863 goriška čitalnica cesarjev god obhajala z »večerno veselico«, z nastopom pevca in pianistke, ${ }^{20}$ dobrih dvajset let kasneje, leta 1885 , pa so ob enaki priložnosti tri ljubljanska društva (Slavec, Dramatično društvo in Sokol) v gledališču pripravila slavnostno akademijo. Izjemen dogodek v zgodovini Glasbene matice je tudi prvi redni koncert v sezoni 1898/99, posvečen spominu cesarice Elizabete. Osrednje slovensko glasbeno društvo oziroma njegovi, po svojem mišljenju večinoma liberalno usmerjeni, člani odbora namreč niso posebej poudarjali legitimizem s posebnimi prireditvami v čast cesarju in državi. Tudi nemški program in angažma solistov dunajske opere je odstopal od društvenih programskih smernic. Posebnost v društveni zgodovini je tudi organizacija "Slavnostnega koncerta na čast gg. častnikom povodom tekmovalnega streljanja c. kr. gorskih polkov v Ljubljani leta 1912«. Dvojezični slovenskonemški programski list je sicer simbolično označil poseben namen koncerta, toda med slovenskimi skladbami na repertoarju ni bilo priložnostnih del. Podobno je bilo dve leti kasneje, ko je Glasbena matica decembra 1914 priredila v Narodnem domu »Dobrodelni koncert ob 66. letnici vladanja cesarja na korist družinam vpoklicanih vojakov«. Spored pevskega večera je uvedla avstrijska himna, Haydnova Cesarska pesem, sledili so sodobni slovenski zbori in samospevi.

Na izrednih koncertih Glasbene matice torej niso bile izvedene posebne priložnostne slavnostne skladbe kot na izrednih koncertih Philharmonische Gesellschaft. Omeniti velja le repertoarno zanimivost iz koncertne zgodovine Glasbene matice. Na sporedu »Prešernove bésede« (!) 19. decembra 1891 v Narodni čitalnici je bil izveden Nedvědov slavospev monarhiji v slovenskem jeziku na besedilo Janka Kersnika (verjetno sina bolj znanega slovenskega pisatelja) Avstrija moja. Moški zbor je objavila založba Glasbena matica istega leta, nekaj let kasneje pa še Družba sv. Mohorja v Celovcu v zbirki Slovenska pesmarica.

Tudi v opusu skladatelja Stanka Premrla najdemo priložnostno skladbo, ki je ostala nenatisnjena, verjetno tudi neizvedena. V letu pred prvo vojno - na avtografu je zapisan datum 25. sept. 1913 - je Stanko Premrl napisal skladbo za mešani zbor, bariton solo in klavir Kranjska zopet z Avstrijo. 1813-1913 na besedilo Josipa Debevca.

19 Evgen Lampe. 'Razne stvari'. V: Dom in svet 11/17 (1898), 544.

20 Novice gospodarske, obrtniške in narodne 21/34 (1863), 277. 


\section{Slava Slovanom! ${ }^{21}$}

Konservativne težnje staroslovenskega političnega programa po letu 1848 označujejo po eni strani lojalnost monarhiji ter po drugi strani načrti za povezovanje s slovanskimi narodi. V primerjavi s slavilnimi pesmimi v čast državi oziroma cesarju in njegovi družini, s katerimi so ustvarjalci kazali vdanost monarhiji, je kvantitativno mnogo večji delež pesmi, nastalih po letu 1848, posvečen poveličevanju ideje slovanske vzajemnosti in združevanja slovanskih narodov. ${ }^{22}$ Zavedanje slovanskih korenin je bilo prehodna stopnja v razvoju izvirne slovenske zavesti. V načrtih za rast slovenske kulture in celo v načrtovanju slovenskega knjižnega jezika se je kazala »slovanska naravnanost«, saj, kot pojasnjuje Breda Pogorelec, naj bi bil skupni knjižni jezik po eni strani znak narodove politične povezanosti; s svojo podobo naj bi izpričeval "slovanskost « in tako povezal Slovence s slovansko družino jezikov in narodov. ${ }^{23}$

Predanost slovanski ideji se je kazala kot idejna in tematska naravnanost v literarnih delih. Občutek ogroženosti slovenstva zaradi večjega političnega pritiska v času Bachovega absolutizma je konec petdesetih let 19. stoletja k pisanju neposredno spodbudil nekatere literarne in glasbene ustvarjalce. Pripadnost »slovanski domovini« je čutil tudi pravnik, politik ter ljubiteljski pesnikovalec in skladatelj Miroslav Vilhar. Napisal je propagandni besedili Slavjanom in Slave dom in ju uglasbil za petje s klavirjem.

Domovinske pesmi so bile eden izmed osrednjih ciklov poezije Simona Jenka. Recepcijsko najbolj uspešne so tiste, ki so bile uglasbene. Dve med njimi sta pridobili status himne: Naprej, ki jo je uglasbil Davorin Jenko leta $1860^{24}$ in Adrijansko morje, ki jo je uglasbil Anton Hajdrih in je bila izdana leta 1876. Njuno zastopanost na repertoarju različnih zborov in pevskih društev v desetletjih po nastanku odkrivajo ohranjeni mnogi prepisi in kopije z društvenimi žigi ter natisi v različnih pesmaricah, ki so izhajale v njuni stopetdesetletni zgodovini, njuno prisotnost na nacionalno pomembnih prireditvah kažejo ohranjeni sporedi. Časopisni viri pišejo o močnih afektih, ki so jih sprožale izvedbe teh pesmi pri množicah, še zlasti budnice Naprej. Njena aktivistična funkcija je bila neizpodbitna, status neuradne "narodne himne« je bil ohranjen mnoga desetletja. Angažiranost in aktualnost te skladbe kaže, kako je politična misel vplivala na recepcijo in percepcijo glasbe.

Čeprav izrazito zunajglasbeno tendenco in politično angažiranost razkriva najprej vsebinska naravnanost besedila, pa je imala enakovredno aktivacijsko moč tudi melodija. Po navedbah Gojmirja Kreka kaže tipičen postopek za narodno-navduševalne pesmi. ${ }^{25}$

21 V arhivu skladatelja Antona Hajdriha, ki ga hrani Narodna in univerzitetna knjižnica v Ljubljani, se nahajajo tudi razmnožene strani njegovega zbora z naslovom Zbor Slava Slovanom! in žigom »Jugoslovansko napr. akad. društvo 'Jadran'«. Izvirnik tega moškega zbora na besedilo Jožeta Virka ima naslov Slava Slovencem! in ga je skladatelj objavil že leta 1876 v zbirki Jadranski glasovi. Ta primer znova potrjuje pomembnost besedila v glasbi za politično rabo in po drugi strani tudi to, da je bila slovanska zavest, značilna za politično misel po letu 1848 , znova aktualna na začetku 20. stoletja.

22 Irena Gantar Godina navaja, da se je predanost slovanski ideji in zavzemanje za slovansko sodelovanje na Slovenskem začelo že konec 18. stoletja z narodnim preporodom. Ideja političnega združevanja s Slovani, še posebej Južnimi Slovani je v slovenski politični misli imela do prve vojne imela tri razvojne oblike: avstroslavizem (do 1860), panslavizem (1860-1905) in novoslavizem (po 1905). Gl. Irena Gantar Godina. 'Oris slovensko-slovanskih stikov do 1914'. V: XXXII. seminar slovenskega jezika, literature in kulture, 24. 6.-13. 7. 1996, ur. Aleksandra Derganc. Ljubljana: Filozofska fakulteta, Oddelek za slovanske jezike in književnosti, 1996, 195-203.

23 Breda Pogorelec. "Slovanska« ali »slovenska« naravnanost načrtovanja slovenskega knjižnega jezika v drugi polovici 19. stoletja'. V: XXXII. Seminar slovenskega jezika, literature in kulture, 24. 6.-13. 7. 1996, ur. Aleksandra Derganc. Ljubljana: Filozofska fakulteta, Oddelek za slovanske jezike in književnosti, 1996, 53-54.

24 Več o skladbi gl.: Dragotin Cvetko. Davorin Jenko. Ljubljana: Partizanska knjiga (Znameniti Slovenci), 1980, 41-59.

25 Gojmir Krek. 'Prinos k motivični literaturi naše himne »Naprej«. V: Novi akordi 12/1-2 (1913), 16. 
O vitalni moči napeva in recepciji pričajo inštrumentalne izvedbe in številne priredbe, ki jih hrani Narodna in univerzitetna knjižnica. Transkripcije Jenkove skladbe Naprej za različne zasedbe - za enoglasni zbor in orkester, za klavir in petje, za klavir, za tamburaški orkester, za pihalni orkester, za veliki orkester - so nastajale v zadnjih desetletjih 19. in še v prvih desetletjih 20. stoletja. Skoraj pol stoletja po nastanku izvirne Jenkove skladbe je bila v reviji Novi akordi objavljena klavirska skladba Fantazija po motivih Dav. Jenkove pesmi »Naprej«, ki jo je napisal Benjamin Ipavec. Vse te priredbe znova potrjujejo relevantnost recepcije za status te "narodne himne«, ki ga dvomi o izvirnosti napeva niso omajali. ${ }^{26}$ Gl. Primer 4.

Ob budnici Naprej je identifikacijski pomen za slovenski narod imela še himna panslavizma, ki so jo Slovenci po letu 1848 prepevali v prevodu Hej Slovenci. Obema pesmima so pridali oznako "narodna ${ }^{27}$ Ponarodelost obeh pesmi je odraz značilnosti, ki so imanentne množičnim pesmim. Njun funkcionalizem je izkazovala pomembnost interpretacije. Aktivna vloga zbranih poslušalcev - množice, ki je pripevala, je bila kvantitativen pokazatelj učinkovitosti. Na množičnem narodnem slavju ob odkritju Prešernovega spomenika leta 1905 se je po navedbah poročevalca »iz tisoč in tisoč grl glasila 'Hej Slovani', nato pa je godba zaigrala še 'Naprej zastava Slave'«. ${ }^{28}$

Največji delež izvirnih zborov za politično rabo na besedila, ki so propagirala idejo slovanstva, je nastal v šestdesetih letih 19. stoletja. Med recepcijsko bolj uspešnimi, ki so kasneje afirmirali idejo vzajemnosti južnih Slovanov, velja omeniti skladbo Frana Serafina Vilharja Slovenec, Srb, Hrvat na besedilo Dragutina Boranića, ki je ohranjena v ljubljanski Narodni in univerzitetni knjižnici v številnih natisih in prepisih. Njen pomen razkrivajo oznake kot »himna slovensko-hrvaške omladine«, »himna na sestanek slovenskih in hrvaških abiturienta" (1891) in »jugoslavenska himna slobode« (1918). Skladba je bila natisnjena tudi v zborovski zbirki založbe Glasbena matica (1922).

Spregledana zanimivost v slovenski glasbeni zgodovini so posamezne inštrumentalne skladbe s programskimi naslovi, ki jasno razkrivajo zunajumetniško spodbudo, vendar pa niso bile namenjene politični rabi. Vse te skladbe so plod iskrenega navdušenja nekaterih glasbenih ustvarjalcev za idejo povezovanja slovanskih narodov. Po navedbah Josipa Mantuanija so bile že leta 1848 in 1849 pogosto na sporedih promenadnih koncertov narodne straže inštrumentalne skladbe mladega Kamila Maška Slaven-Polka, Slaven-Potpourri, Slovenen-Polka, Serben-Polka. ${ }^{29}$ (Zdi se bolj verjetno, da gre za dela njegovega očeta Gašparja Maška, ki je imel tedaj mnogo več glasbenih izkušenj in je od leta 1848 sodeloval tudi pri bésedah Slovenskega društva.)

Sokolstvo, nacionalistično telovadno gibanje slovanskih narodov, je bilo odgovor na nemške nacionalistične telovadne organizacije. ${ }^{30}$ Južnemu Sokolu, ustanovljenemu leta 1863, sta posvetila priložnostni skladbi Miroslav Vilhar (Sokolovo popotnico je leta 1864 natisnil Blaznik) in Gustav Ipavec (moški zbor Sokolska na besedilo Davorina

26 Uglasbitvi sta bili objavljeni v zbirki Pesmi Miroslava Vilharja, ki je izšla leta 1852 v Ljubljani.

27 Pomen obeh pesmi in njuna recepcija sta razvidna iz ohranjenih programov in časopisnih poročil. Bésedo v postojnski čitalnici leta 1862 je po navedbah časopisnega poročevalca uvedel Naprej, zaključila narodna (podčrtala avtorica članka) 'Hej Slovani'. Gl. Novice gospodarske, obrtniške in narodne, 20/1862, 207-208.

28 Fran Zbašnik. 'Odkritje Prešernovega spomenika'. V: Ljubljanski zvon 25/12 (1905), 638.

29 Josip Mantuani. 'Mašek Kamilo'. V: Slovenski biografski leksikon, 2. zv. Ljubljana: Slovenska akademija znanosti in umetnosti, 1952, 69 .

30 Ervin Dolenc, Milan Pahor in Edi Majaron. ‘Sokolstvo'. V: Enciklopedija Slovenije, 12 zv. Ljubljana: Mladinska knjiga, 1998, 144-147. 


\section{Fantazija}

po motivih Dav. Jenko ve pesmi „Naprej."
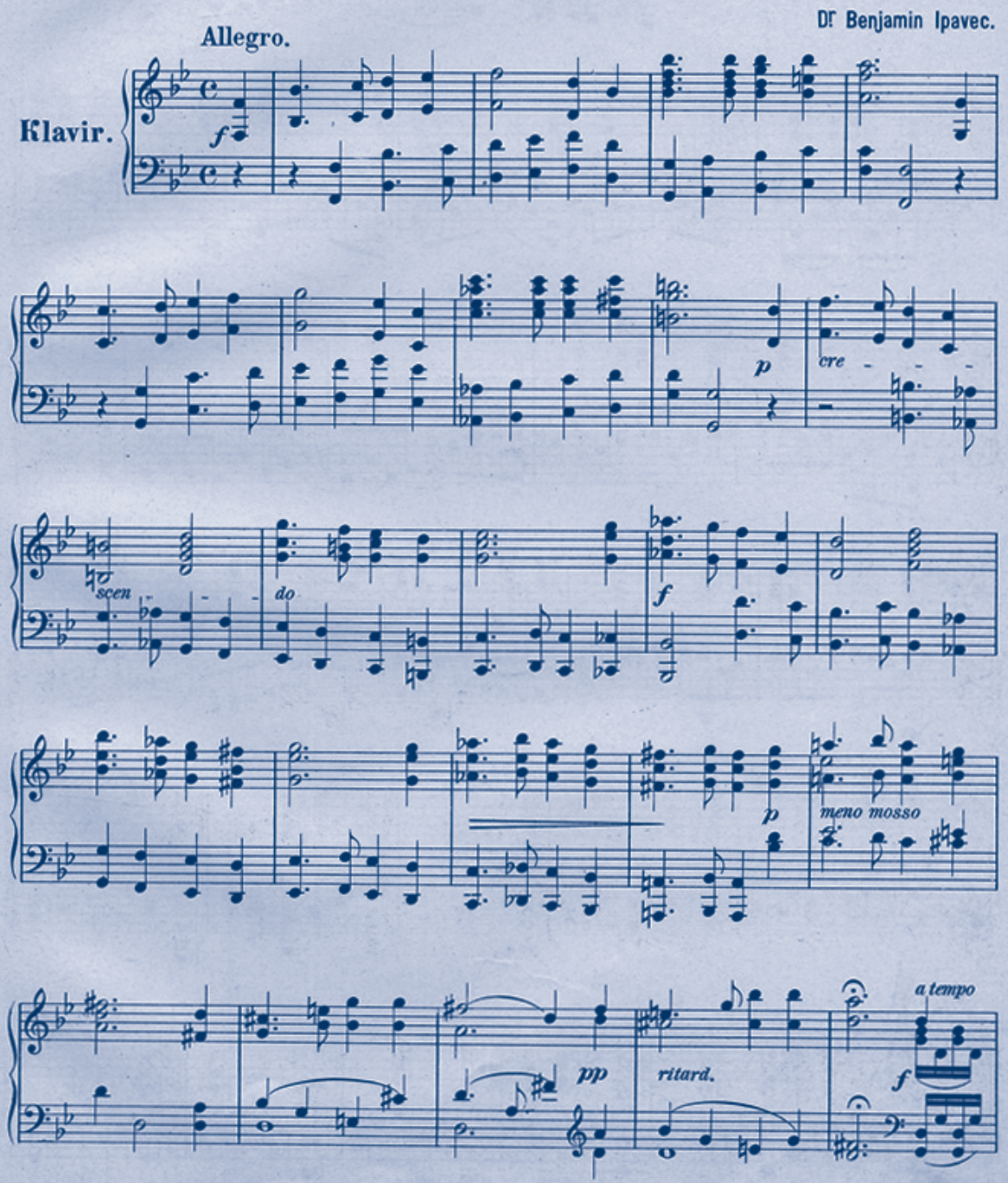

N. A.V. 6.

Primer 4.

Benjamin Ipavec: Fantazija. (Novi akordi, 5/6 [1906], str. 61.) 
Trstenjaka ni bil natisnjen). Revija Novi akordi je leta 1910 objavila klavirsko skladbo Evgena Bunca Sokolska koračnica. Funkcija skladbe kot zvočne kulise je jasno opredeljena v naslovu.

V šestdesetih letih 19. stoletja je na bésedah v Gradcu in Celju Benjamin Ipavec igral svoje klavirske skladbe z emblematičnimi naslovi Slovanska četvorka (Gradec 1862), Fantazija o narodnih pesmih slovanskih (Gradec, Celje 1862). ${ }^{31}$ Leta 1863 je časopis Novice oglaševal ponudbo za nakup Ipavčeve skladbe Kadrilja po jugoslovanskem napevu za klavir. ${ }^{32}$ Glasbena matica je leta 1878 objavila v samostojni izdaji kratko klavirsko skladbo Benjamina Ipavca z naslovom Slavjanka. Mazurka za glasovir. V rokopisu, na katerem je zapisan datum 23. 8. 1885, so ohranjene tudi Gerbičeve Južnoslovjenske balade za klavir četveroročno op. 23.

Na začetku 20. stoletja je klavirske skladbe z naslovi, ki jasno izpričujejo avtorjevo naklonjenost slovanstvu, objavila tudi revija Novi akordi. Njen urednik Gojmir Krek je objavil svoji skladbi Slovanski capriccio (1901) in Slovanski capriccietto (1908) ter skladbo Josipa Vedrala Slovanska koračnica (1902). V primerjavi s prej navedenimi skladbami te $s$ politično idejo povezuje le zunanji predznak, glasbeno gradivo ni folklorno obarvano. Za domačo rabo je založnik Schwentner leta 1907 izdal zbirko Slovanske himne, ki jih je za klavir in petje priredil Fran Gerbič. Glasbeni folklorizem se kot ustaljena manira Foersterjeve ustvarjalnosti "za rabo « kaže tudi v njegovi klavirski skladbi z naslovom Slovanska sonata. ${ }^{33} \mathrm{Na}$ rokopisu skladbe, ki ga hranijo v Narodni in univerzitetni knjiŽnici v Ljubljani, je pripisana letnica 1914. Skladba je razdeljena na štiri stavke z naslovi: Slovenska, Češka, Polska in Hrvatska - Srbska. Pri zadnjem stavku je naslov prečrtan in napisano Jugoslavija. »Slovenskost « prvega dela razkriva citat ljudske pesmi Oj ta vojaški boben.

Jasen znak neposrednega delovanja političnega prostora na glasbeno ustvarjalnost sta tudi naslova dveh rokopisnih orkestralnih skladb Frana Gerbiča Jugoslovanska rapsodija op. 60 (1904) in Jugoslovanska balada op. 21. št 2 (1910). Ideja jugoslovanstva je na Slovenskem postala bolj priljubljena po aneksijski krizi leta 1908. Prav takov rokopisu je ohranjena budniška zborovska skladba Stanka Premrla z naslovom Jugoslovanska himna, na kateri je s svinčnikom pripisana letnica 1920. Sporočilnost besedila, ki se začne »Bratje! V Triglavu ognji gore [...]«, je jasna, melodija je le njegova prenašalka. Priložnostna skladba je bila napisana spontano po obrazcu preteklih budniških skladb.

Zavzemanje za kulturno povezovanje s slovanskimi narodi kažejo tudi koncertna in založniška politika Glasbene matice, dela slovanskih skladateljev na programu njenih koncertov, gostovanja slovanskih umetnikov ter nekatere objave skladb. Ob priliki drugega vsesokolskega zleta v Ljubljani in štiridesetletnice ljubljanskega Sokola leta 1904 je Glasbena matica priredila "Reprezentativen koncert na čast slovanskim gostom «. ${ }^{34}$ Na sporedu koncerta ni bilo zborovskih skladb z izrazito slovansko-budniško tematiko,

\footnotetext{
Novice gospodarske, obrtniške in narodne $20 / 28$ (1862), 235.

Novice gospodarske, obrtniške in narodne 21/10 (1863), 23.

Na rokopisu Foersterjeve skladbe Slovanska sonata je s svinčnikom pripisano, da je založba Edition Slave (imela je izpostavo v Zagrebu) skladbi pripisala oznako suita namesto "sonata*.

34 Stopetdeset pevcev zbora Glasbene matice je izvajalo dela Antona Hajdriha, Davorina Jenka, Antona Foersterja, Antona Nedvěda, Gojmirja Kreka in Antona Lajovica. Gl. tudi poročilo: Vladimir Foerster. 'Slavnostni koncert „Glasbene Matice«". V: Ljubljanski zvon 24/1904, 509.
} 
pač pa je slavnostni, tujcem namenjeni koncert vodila namera predstaviti izbor skladb pomembnejših slovenskih skladateljev. Z namenom podpore ideji jugoslovanske vzajemnosti in poživljanja skladateljskega delovanja je Glasbena matica leta 1907 razpisala častne nagrade za nove izvirne slovenske, hrvaške ali srbske skladbe. ${ }^{35}$ Častno nagrado je dobila skladba Frana Serafina Vilharja Na Ozlju gradu na besedilo Mihovila Nikolića, ki jo je objavila Glasbena matica istega leta v zbirki 14 moških in mešanih zborov. ${ }^{36} \mathrm{Ob}$ 50-letnici »narodne himne« Naprej je Glasbena matica leta 1910 priredila izredni slavnostni koncert na čast njenemu ustvarjalcu in svojemu častnemu članu Davorinu Jenku. Kljub politično neaktualnemu in za državno himno neustreznemu besedilu, je pesem po razpadu Avstroogrske postala del tridelne himne države Srbov, Hrvatov in Slovencev. Med njimi le slovenski del ni bil slavospev slovenskemu narodu ampak propaganda za idejo slovanstva, ki je bila odraz preteklega staroslovenskega političnega mišljenja.

Čeprav sta glasba in politika navidez nezdružljivi entiteti, je vpliv politike na glasbo in glasbeno življenje jasen in razviden še posebej v 19. stoletju, ko je bil upor proti dominaciji nemške glasbe $\mathrm{v}$ prizadevanjih za nacionalno glasbo v ospredju ne samo na Slovenskem ampak tudi v glasbeno bolj razvitih evropskih deželah. V slednjih je temeljil na drugačnih glasbenih osnovah, se izrazil prej in na drugačen način. Za specifiko slovenskega glasbenega in političnega prostora po letu 1848 je bila značilna tudi tesna vez osebnosti, ki so se ukvarjale s politiko in kulturnim življenjem, nekateri slovenski politiki so celo pisali besedila narodnoprebudnih pesmi. Glasba ni bila samostojna, bila je zavezana kulturni in s tem politični propagandi. Predznak neposrednega delovanja političnega prostora na glasbeno ustvarjalnost so poleg besedil in naslovov tudi posvetila političnim veljakom na zbirkah oziroma posameznih skladbah.

Težko je natančno določiti, do kam je segala na glasbeno delovanje politična zavest. Nedvomno je, da slovenska politika po letu 1848 ni imela neposrednega vpliva na sam glasbeno-umetniški razvoj, pač pa na recepcijo in percepcijo glasbe. Njen utilitarno zastavljen kulturni program je neposredno stimuliral glasbeno ustvarjalnost. Priznane in ustaljene norme glasbenega oblikovanja, ki jih je podpirala konservativna staroslovenska politika z Bleiweisom na čelu, so vodile ustvarjalce v pisanje v vseh ozirih preprostih pesmi, oprtih na ljudsko pesem. Glasbeni folklorizem je postal uveljavljena manira, ki se je po ločitvi političnih duhov konec stoletja ohranila v miselnosti konservativne struje.

Konservativne težnje staroslovenskega nacionalnega političnega programa po letu 1848 označujejo po eni strani lojalnost monarhiji ter po drugi strani načrti za povezovanje s slovanskimi narodi. Drugačno podobo in pomene kot pretežni del izvirne ustvarjalnosti »V službi naroda« kaže priložnostna glasba za politično rabo z izrazito zunajumetniško tendenco - kantate v čast »herojem« slovenstva - pesnikoma Valentinu Vodniku in Francetu Prešernu ter politiku Janezu Bleiweisu, priložnostne pesmi v slavo monarhiji, v čast cesarju, njegovi družini ter hvalnice slovanstvu. Patriotske hvalnice stari Avstriji predstavljajo v primerjavi z narodno-prebudnimi zbori na besedila, ki opevajo lepote

35 Anton Štritof. Izvestje »Glasbene Matice«v Ljubljani o 35. društvenem letu 1906/7. Ljubljana: Glasbena matica, $1907,22$.

36 VII. Zapisnik»Glasbene Matice«22. decembra 1907. 
slovenske dežele, le zanemarljiv delež in umetniško nepomemben tedanje slovenske glasbene ustvarjalnosti - od pomladi narodov do razpada monarhije jih je nastalo manj kot dvajset. Pisali so jih priseljeni češki glasbeniki K. Mašek, Nedvěd, Foerster in priloŽnostni, manj pomembni ustvarjalci, ki jim je bil blizu legitimizem staroslovenskega političnega programa. Nastale so ob posebnih priložnostih in obletnicah, večinoma so bile namenjene enkratnemu izvajanju. V nasprotju z maloštevilni pesmimi v čast cesarju in monarhiji je bil kvantitativno večji delež pesmi namenjen propagiranju ideje slovanske vzajemnosti. Narodno zavedni slovenski glasbeni ustvarjalci so jih pisali zlasti v petdesetih in šestdesetih letih 19. stoletja. Tovrstne pesmi s politično angažirano vsebino lahko glede na rabo označimo kot "politične pesmi«. Simptomatičen primer takšne pesmi s politično angažirano vsebino je budnica Naprej zastava Slave, ki je najprej služila kot propaganda panslavizmu in $\mathrm{v}$ kasnejših desetletjih zaradi recepcije pridobila pomen narodne himne.

Funkcionalnost priložnostnih hvalnic se kaže na ravni izbora in oblikovanja glasbenega gradiva, na izvedbeni in na pomenski ravni. Ne glede na podrejenost glasbenega oblikovanja namenu, pa je bila estetska vrednost takšnih skladb rezultat skladateljeve ustvarjalne moči. Plod manj pomembnih priložnostnih ustvarjalcev je bila največkrat naivna, trivialna glasba brez glasbenega okusa. Čeprav so priložnostne himne v čast monarhiji, cesarju in panslavizmu nepomembne za sam glasbeni razvoj, pa tudi takšna "paraglasbena dela« sodijo v kulturno izročilo. Ne nazadnje glasbena dela v preteklosti niso nastajala $v$ duhovnem, etičnem in idejno praznem prostoru in glasbena zgodovina le niz dogodkov ali posameznih glasbenih del. Preko omenjenih priložnostnih hvalnic lahko recipročno rekonstruiramo del kulturne zgodovine. So torej tudi indikatorji za zunajumetniške dejavnike, ki so vplivali na glasbo v najširšem pomenu besede. 